\title{
A PRÁTICA DA RELIGIOSIDADE COMO FATOR DETERMINANTE PARA UMA VIDA SAUDÁVEL: O CARÁTER RELIGIOSO COMO MANTENEDOR DA SAÚDE FÍSICA E MENTAL
}

\section{REVISÃO INTEGRATIVA}

FECURY, Amanda Alves ${ }^{1}$

AQUINO, Elizabete Steyse Rocha ${ }^{2}$

OLIVEIRA, Jessica Lopes ${ }^{3}$

GONÇALVES, Vitória Nazaré Dias ${ }^{4}$

FECURY, Amanda Alves. Et al. A prática da religiosidade como fator determinante para uma vida saudável: $O$ caráter religioso como mantenedor da saúde física e mental. Revista Científica Multidisciplinar Núcleo do Conhecimento. Ano 05, Ed. 03, Vol. 07, pp. 69-79. Março de 2020. ISSN: 2448-0959, Link de acesso: https://www.nucleodoconhecimento.com.br/saude/pratica-da-religiosidade

\section{RESUMO}

Este estudo buscou quantificar e analisar produções científicas que discorram sobre o impacto positivo da vivência da religiosidade na manutenção e recuperação da saúde, nas várias faixas etárias, em seus aspectos multidimensionais. Foi realizado levantamento bibliográfico utilizando as palavras/termos: religiosidade, saúde mental, proteção da saúde e profissional de saúde; nas bases de dados LILACS, biblioteca eletrônica SCIELO e Portal de Periódicos CAPES, considerando o período de publicação de 2008 a 2019. A partir dessa busca, foi realizada a revisão integrativa de

${ }^{1}$ Docente do curso de Medicina na Universidade Federal do Amapá.

2 Discente do curso de Medicina na Universidade Federal do Amapá.

${ }^{3}$ Discente do curso de Medicina na Universidade Federal do Amapá.

${ }^{4}$ Discente do curso de Medicina na Universidade Federal do Amapá. 
18 trabalhos, utilizando como critério de inclusão os idiomas inglês e português, a disponibilidade online do trabalho e a compatibilidade com o tema do estudo. De modo geral, foi verificada a reinterpretação positiva do estado de sofrimento, onde a religiosidade "dá suporte ao sofrer", além de indicar melhores índices de adesão aos tratamentos em situações de comorbidades. Atualmente, o público jovem também tem se inserido nessa visão positiva relacionada à religiosidade e o processo saúde $\mathrm{X}$ doença. Com relação aos idosos, a religiosidade tem destaque na manutenção, mas principalmente na recuperação da saúde. Além da prática religiosa particular, os grupos religiosos têm papel de destaque, representando uma rede de apoio social muitas vezes determinante no êxito do bem-estar biopsicossocial.

Palavras chaves: Religiosidade, saúde mental, proteção da saúde, profissional de saúde.

\section{INTRODUÇÃO}

A religiosidade é caracterizada como um sistema organizado, onde crenças, práticas, rituais e símbolos são utilizados como portal de acesso ao transcendente, sendo organizada em grupos bem estabelecidos (Zanetti, 2018). A espiritualidade surge como sentimento pessoal, podendo expressar-se na forma religiosa ou não, mas estão engajadas, dando significado à vida (Campos, 2012).

As diversas religiões, particularmente de cunho cristão, têm princípios filosóficos semelhantes, dessa forma, as pessoas encontram uma unidade de princípios onde desenvolvem sua fé, que passa a influenciar nos vários aspectos de suas vidas, como o ético, moral, auto percepção existencial, relações íntimas e com o outro, e também a perspectiva sobre o aspecto saúde e doença (Souza, 2009).

A ligação entre saúde e religiosidade tem origem que se confunde com a história evolutiva da humanidade. O cristianismo instituiu o cuidado aos doentes por comunidades religiosas e influenciou diretamente a criação de casas de apoio, estando preceitos cristãos enraizados na formação dos profissionais de saúde. Após o domínio exercido pela igreja católica, que delimitou uma ruptura de mais de 300 
anos entre religiosidade e ciência, a comunidade científica passou a se interessar pelo campo religioso. Especialmente no âmbito da saúde, nos seus aspectos físicos e psíquicos, destacam-se os benefícios que o cultivo da fé traz para o enfrentamento de situações de vulnerabilidade, evidenciando a necessidade de estreitamento das relações desses dois aspectos da vida humana (Souza, 2009; Zanetti, 2018).

As frequentes pesquisas científicas têm demonstrado que o maior cultivo religioso está associado a maiores níveis de bem-estar geral, menor prevalência de depressão e distúrbios mentais, menor abuso de álcool e drogas, menor incidência de suicídio, melhor qualidade de vida, maior sobrevida e menor tempo de internação (Tomasso, 2011). Comumente os benefícios da prática religiosa estão associados a pessoas sob estresse ou em situações de fragilidade, como idosos, pessoas com deficiência e doenças clínicas. Porém, têm-se demonstrado o impacto também em adolescentes e adultos sem fragilidades comuns (Stroppa, 2008).

No Brasil, segundo o Instituto Brasileiro de Geografia e Estatística - IBGE (2010), apenas cerca de 7,4\% da população não tem religião (IBGE, 2010). Assim, verifica-se a importância dos profissionais de saúde, especialmente a atenção do Sistema Único de Saúde, através da sua Política Nacional de Humanização, no cuidado que inclua e valorize a dimensão religiosa. Visando, dessa forma, alcançar um dos seus princípios que é a integralidade, com a visão holística do ser humano, esse cuidador deve passar a ser sujeito capaz de acolher, refletir, reconhecer e desempenhar assistência sensível as necessidades daqueles que são cuidados (Oliveira, 2018).

Conforme o que foi exposto, este trabalho busca destacar os impactos positivos da religiosidade na saúde, em suas dimensões física e mental, nas faixas etárias adolescente, adulta e idoso. Busca também refletir o papel dos profissionais de saúde na valorização desse contexto.

\section{METODOLOGIA}

Consiste em um estudo de revisão integrativa de literatura, que elucida os conhecimentos atuais sobre um tema específico, pois busca identificar, analisar e 
sintetizar resultados de estudos independentes sobre o mesmo assunto. Em temáticas da saúde, possibilita a incorporação da aplicabilidade de estudos significativos na prática, pois envolve desde a definição do problema clínico, como a identificação das informações necessárias, a condução da busca de estudos na literatura e sua avaliação crítica, identificação da aplicabilidade dos dados advindos das publicações e a determinação de sua utilização para o paciente (Campos, 2012; Souza, 2010).

O processo de elaboração da revisão integrativa consiste em seis etapas: a primeira é a elaboração da pergunta norteadora, inclui a definição dos participantes, as intervenções a serem avaliadas e os resultados a serem mensurados. Sua construção deve estar relacionada a um raciocínio teórico e ser embasada em definições já apreendidas pelo pesquisador. A segunda etapa é a seleção da amostra na literatura, feita de forma ampla e diversificada, com critérios de inclusão e exclusão que garantam a representatividade da amostra (Souza, 2010).

O próximo passo foi a coleta de dados, a partir de instrumento previamente elaborado. Em seguida, fez-se a análise crítica dos estudos incluídos, a partir de abordagem organizada para identificar as características de cada estudo. As próximas etapas foram discussão dos resultados e apresentação da revisão integrativa (Souza, 2010).

O levantamento bibliográfico foi feito nas bases de dados LILACS, biblioteca eletrônica SCIELO e Portal de Periódicos CAPES, buscando temas relacionados à religiosidade e saúde. Os descritores utilizados foram: religiosidade, saúde mental, proteção da saúde e profissional de saúde.

Foram considerados como critérios para seleção da amostra dissertações e artigos completos, publicados em periódicos nacionais e internacionais de língua portuguesa e inglesa, entre 2008 e 2019, que possuem abordagem da religiosidade e sua relação com a saúde, assim como o manejo por parte dos profissionais frente às constatações, consideradas de interesse a essa área.

A coleta de dados foi feita a partir da leitura do material, sendo selecionados aqueles que foram identificados como relevantes para o alcance dos objetivos propostos. 
A classificação foi feita de forma individual, considerando as informações a partir do autor, instituição sede do estudo, tipo de publicação, objetivo, intervenções realizadas e resultados. A avaliação dos dados obtidos ocorreu de acordo com seu conteúdo, por descrição analítica.

\section{RESULTADOS E DISCUSSÃO}

Inicialmente, foram encontrados 127 artigos na biblioteca virtual Lilacs, 5 no SciELO, e 400 no Portal de periódicos CAPES, para os descritores "religiosidade", "saúde mental", "proteção da saúde" e "profissional de saúde", que foram utilizados em combinações alternadas de "religiosidade e saúde mental", "religiosidade e proteção da saúde" e "religiosidade e o profissional de saúde". A busca nas duas bibliotecas e no portal de periódicos totalizou 532 trabalhos, sendo os artigos duplicados contabilizados apenas uma vez. Assim, foram selecionados 18 estudos que contemplavam todos os aspectos para leitura completa.

A leitura crítica dos trabalhos incitou a divisão em subtemas para melhor exposição dos objetivos propostos. Dessa forma, a análise pôde ser feita pontualmente, identificando os vários nuances envolvidos na relação entre religiosidade e saúde, conforme exposto na sequência:

\subsection{RELIGIOSIDADE E COPING}

Coping é uma palavra inglesa que significa "lidar com". O coping religioso é um conceito utilizado nos estudos da religiosidade e espiritualidade. Esse termo se refere aos comportamentos baseados em crenças religiosas que ajudam as pessoas a solucionar problemas, além de neutralizar emoções negativas em conflitos e situações de estresse (Foch, 2017).

Pargament e colaboradores elaboraram uma escala de coping religioso e espiritual. Conforme essa escala, a religião possibilita variadas estratégias de coping, que podem ser classificados em positivos e negativos, onde os positivos são utilizados predominantemente (Stroppa,2008). 
Os exemplos de coping positivo são: a reavaliação religiosa benevolente, onde um indivíduo busca um ensinamento divino no ocorrido; coping religioso de colaboração, onde a presença de Deus é sentida atuando junto; foco religioso, consistindo na reavaliação da postura baseado nos ensinamentos religiosos; ajuda através da religião, onde a pessoa ajuda espiritualmente outras pessoas; apoio espiritual, sendo o encontro do conforto, orientação e proteção em Deus; apoio de membros da instituição religiosa, onde o grupo é local de auxílio; perdão religioso, que consiste em buscar força em Deus para perdoar outras pessoas; conexão espiritual, significando a busca de proteção e orientação de entidades espirituais (Stroppa, 2008).

\subsection{RELIGIOSIDADE E ADOLESCÊNCIA}

A adolescência é um período onde o bem-estar tem importância preponderante, considerando essa fase por seu caráter ativo e imediatista. As concepções teóricas sobre bem-estar dividem-no em duas perspectivas: o bem-estar eudemônico (bemestar psicológico), traduzido no pleno funcionamento das potencialidades de uma pessoa, incluindo capacidade de pensamento e de bom senso. A segunda perspectiva é o bem-estar hedônico (bem-estar subjetivo), considerado positivo quando o indivíduo apresenta altos níveis de satisfação com a vida, altos níveis de emoções positivas e baixos níveis de emoções negativas (Silva, 2017).

Há evidências de que a religiosidade é componente na construção do bem-estar subjetivo entre adolescentes. Existe relação significativa entre satisfação de vida, afetos positivos e participação em atividades religiosas. Ocorre maior satisfação com os relacionamentos interpessoais, seja familiar ou com os pares, melhores índices de comunicação e felicidade (Silva, 2017).

No âmbito familiar, o envolvimento religioso da família como um todo aproxima e minimiza conflitos, possibilita o enfrentamento de situações de sofrimento e estresse, além de influenciar diretamente na formação religiosa dos jovens. Dessa forma, a religiosidade estaria atrelada à estruturação e organização familiar, superação de dificuldades e consequentemente seria fator protetivo para comportamentos de risco na adolescência (Farinha et al., 2018). 
Dos comportamentos de risco, existem evidências que indicam o início do uso de tabaco aos 16 anos, e do álcool aos 17, em média. As bebidas alcoólicas são as substâncias psicotrópicas mais utilizadas pelos adolescentes. O consumo em "binge" vem crescendo entre os adolescentes, em faixas etárias cada vez menores e em ambos os sexos. Pesquisas afirmam que a religiosidade, junto com fatores como família, forte envolvimento com atividades escolares e disponibilidade de informações, são fatores protetivos para evitar esta prática (Guimarães, 2018; Queiroz, et al.; 2015).

Os impactos positivos da religiosidade na adolescência justificam-se ainda pelo fato de que vivenciar a religiosidade possibilita suporte social, propósito e significado para a vida, fatores que potencializam o bem-estar subjetivo. Considerando que a maioria dos jovens institui a felicidade como muito importante em suas vidas, percebe-se a necessidade de altos níveis de bem-estar subjetivo, como elemento que possibilita lidar com as dificuldades da vida de forma mais positiva e adaptativa. Funciona ainda como elemento norteador, tão necessário a essa fase de transição para a idade adulta, tornando o indivíduo consciente e crítico de suas escolhas e evitando abusos a si próprio (Silva, 2017).

\subsection{RELIGIOSIDADE E IDADE ADULTA}

A fase adulta é caracterizada pela ocorrência de maior estabilidade emocional, valores estabelecidos e escolhas conscientes. Assim, a religiosidade atua como fator de proteção menos decisivo que nas demais faixas etárias, na maior parte dessa população. Porém, de forma não menos importante, a partir da perspectiva que os hábitos religiosos funcionam como combustível para o equilíbrio do ser humano, mesmo fora de estados de fragilidade (Queiroz, et al.; 2015; Lazari et al., 2017).

A tradição religiosa instituída, cultiva a necessidade da relação pessoal com Deus, essa relação pode impactar diversas áreas da vida humana. A religiosidade é associada a maior aceitação e firmeza, gerando paz, autoconfiança e uma imagem positiva de si mesmo. Contribui ainda para o bem-estar social, sendo os mecanismos de destaque para esta realização a integração social, através da comunidade religiosa, e a regulação social, a partir das normas estabelecidas por estas 
comunidades religiosas e que são reforçadas no convívio (Campos, 2012; Stroppa, 2008).

Associado a isto está a melhor qualidade de vida que pessoas religiosas possuem, onde um dos fatores que contribuem para isto é a não utilização de álcool e drogas, ou seu uso diminuído. Destaca-se o papel protetivo da religiosidade em públicos de baixa escolaridade, moradores de territórios vulneráveis e com elevada circulação de álcool e drogas (Lazari et al., 2017). Junto a isto, a religiosidade é peça fundamental no tratamento holístico, preconizado por diversas teorias, na recuperação do vício e saúde de dependentes químicos (Oliveira et al., 2017).

Ainda no quesito qualidade de vida, a religiosidade está associada a formação de comportamentos protetivos e que conduzem à saúde, como o cumprimento de ordens médicas e a realização de exercícios físicos, diminuindo a incidência do estresse e doenças agudas e crônicas (Campos, 2012; Stroppa, 2008).

Existe também forte associação positiva entre o envolvimento religioso e saúde mental, incluindo desde transtornos leves, como ansiedade, moderados, como os quadros depressivos e graves, como as psicoses. Verificou-se que indivíduos pouco religiosos apresentam o dobro de chances de apresentarem transtornos mentais (Campos, 2012).

No âmbito da saúde física, constatou-se que há uma forte ligação da fé com a recuperação de doenças, mesmo em casos onde os pacientes foram desenganados pelos médicos, onde os próprios pacientes atribuíram essa melhora à fé. Quando a fé e as práticas religiosas não alcançam o êxito da cura ou prolongam a vida, elas podem melhorar a qualidade de vida e o propósito de viver (Stroppa, 2008). Portanto, podese concluir que uma das formas de enfrentamento da morte e da doença está associada à força da fé e das crenças religiosas (Oliveira, 2018).

Entende-se que a religião permite uma releitura do sofrimento, Ihe conferindo certa positividade, permitindo para o ser humano a ressignificação de seu sofrimento através de vivências religiosas. Assim, nas diversas situações conflituosas, a 
religiosidade funciona como âncora, trazendo o indivíduo de volta ao estado positivo, cultivado continuamente, conforme suas experiências espirituais (Stroppa, 2008).

\subsection{RELIGIOSIDADE E O IDOSO}

Os idosos representam a faixa etária que mais pratica a religiosidade. O processo de envelhecimento traz limitações, diminuição das atividades, ociosidade e solidão, além da morbidade causada pelas doenças. A religiosidade nessa população traduz-se como estratégia de enfrentamento, especificamente no âmbito emocional, que possibilita o cultivo da resiliência para enfrentar todas as particularidades características do idoso (Ribeiro et al., 2018).

Para o idoso, a fé em Deus dá a certeza de que ele não está desemparado, mesmo na ausência de familiares. O exercício da fé as aproxima desse Ser superior e possibilita a paz e o preenchimento do vazio existencial, sendo o sustentáculo do cotidiano e propiciando a vivência de uma velhice sem preocupações (Reis, 2017).

O idoso cultiva verdadeira gratidão pelas bênçãos alcançadas através da oração, como a manutenção e a recuperação da saúde, assim como o alcance da longevidade. Assim, o decorrer da velhice e os momentos de reclusão ou mesmo solidão, traz à tona o modo de ser próprio de cada idoso, e a comunhão com Deus surge como algo que corre em conjunto com esse momento, compartilha (Reis, 2017).

O cultivo religioso está relacionado ainda a uma melhor manutenção da saúde mental entre os idosos, especificamente os transtornos depressivos e uso de medicamentos. Atua além da ressignificação dos estados de sofrimento, também no isolamento e solidão, que são consequentes ou agravam os sintomas depressivos (Vicente et al., 2018).

\subsection{RELIGIOSIDADE E O CUIDADOR}

O atual cenário brasileiro, urge por profissionais que valorizem e enxerguem o ser humano em sua dimensão holística. Profissionais que respeitem e estimulem as diversas práticas religiosas, aliando as técnicas e teorias já consolidadas, ao cultivo 
espiritual que se destaca cada dia mais nos diversos meios científicos (Longuiniere, 2018).

A religiosidade do cuidador também deve ser valorizada, partindo do princípio que os estímulos positivos dessa prática influenciam diretamente nas suas relações interpessoais, propiciando a harmonia e equilíbrio (Longuiniere, 2018).

Nesse sentido, chama-se atenção para o Sistema Único de Saúde, que através da Política Nacional de Humanização (PNH), fomenta a valorização dos usuários, trabalhadores e gestores no processo da construção da saúde. O processo de humanização inclui ainda o estímulo da autonomia, do protagonismo, a corresponsabilidade na produção de saúde e de sujeitos e melhoria e aproximação no contato profissional-usuário (Oliveira, 2018).

O empecilho encontra-se na dificuldade dessas posturas tornarem-se realidade, principalmente no campo prático da saúde. A simples leitura dos programas não é suficiente para isto, sendo necessário treinamento constante, pois, através dessa nova visão busca-se superar o modelo biomédico, inserindo o usuário como protagonista do processo de assistência. Este é um longo e resistente caminho, pois envolve mudanças comportamentais e ruptura com a história de formação individual (Oliveira, 2018).

A política vai além, como consta em seu plano de origem, onde pontua a necessidade da implementação da PNH no eixo da educação permanente em saúde, como conteúdo e/ou componentes curriculares de cursos de graduação, pós-graduação e extensão em saúde. No eixo da informação/comunicação, deve ser inserida no debate à saúde através da ação da mídia e do discurso social amplo (Oliveira, 2018).

Dessa forma, espera-se melhoria na formação e manutenção das práticas desses profissionais, para que este tipo de tema seja uma realidade de forma natural e benéfica, fazendo com que o cuidado se torne integral, e possibilite aos usuários a completude e a maximização do potencial curativo que existe na espiritualidade de cada um (Longuininere, 2018). 


\section{CONSIDERAÇÕES FINAIS}

Os estudos associados à religiosidade apresentam significativa correlação entre esta prática e mudanças de vida positivas, bem como demonstram a importância das formações e dos serviços de saúde estimularem hábitos religiosos.

Sendo assim, compreendendo o paciente de forma integral, tanto no âmbito religioso quanto nos demais, os profissionais de saúde poderão participar da manutenção da sua vitalidade física e mental, ajudando-o, pois, a viver de forma saudável.

\section{REFERÊNCIAS}

FARINHA, Francely Tineli. et al. Correlação entre espiritualidade, religiosidade e qualidade de vida em adolescentes. Revista bioética. Brasília, 26 (4): 567-73, 2018.

FOCH, Gisele F. de Lima. et al. Coping religioso/espiritual: uma revisão sistemática de literatura (2003-2013). Arquivos Brasileiros de Psicologia; Rio de Janeiro, 69(2): 53-71, 2017.

GUIMARÃES, Mariana Oliveira. et al. Religiosidade como possível fator de proteção do "binge drinking" por escolares de 12 anos de idade: um estudo de base populacional. Ciências \& Saúde Coletiva. Diamantina, 23(4): 1067 - 1076, 2018.

LAZARI, Alan Henrique. et al. Famílias em território vulnerável e motivos para o não uso de drogas. Revista Eletrônica de Enfermagem [Internet]. $2017 \quad$ [acesso em: 17/04/19]; 19:a11.Disponível em: http://dx.doi.org/10.5216/ree.v19.38380.

LONGUINIERE, Agnes Claudine D. $\mathrm{L}$. et al. Influência da religiosidade/espiritualidade do profissional de saúde no cuidado ao paciente crítico. Revista Cuidarte, Colombia, 2018; 9(1): 1961-72. 
MURAKAMI, Rose. et al. Religião e saúde mental: desafio de integrar a religiosidade ao cuidado com o paciente. Revista Brasileira de Enfermagem. Brasília, 65(2): 361-7, mar-abr 2012.

OLIVEIRA, Ana Lívia C. Branco. et al. Espiritualidade e religiosidade no contexto do uso abusivo de drogas. Revista Rene, Piauí, 18(2):283-90, mar-abr 2017.

OLIVEIRA, Rafael Moura. et al. Espiritualidade/Religiosidade e o HumanizaSUS em unidades de saúde da família. Revista Brasileira em Promoção da Saúde. Fortaleza, 31(1): 1-8, jan-mar 2018.

QUEIROZ, Nataly da Rocha. et al. Associação entre o consumo de bebidas alcóolicas e tabaco e a religiosidade. Acta Paulista de Enfermagem. São Paulo, 28(6):546-52, 2015.

REIS, Luana Araújo. et al. Religiosidade e espiritualidade nas estratégias de resiliência do idoso longevo no cotidiano. Revista Brasileira de Enfermagem. Salvador, 70(4): 761-6, jul-ago 2017.

RIBEIRO, Laís C. Moreira. et al. Estratégias de Enfrentamento das Doenças por Idosas Hospitalizadas. Psico - USF. Bragança Paulista, v. 23, n. 3, p. 473-482, jul./set. 2018.

SILVA, Doralúcia Gil. et al. Relações entre satisfação com a vida, com a família e com as amizades e religiosidade na adolescência. Estudos Interdisciplinares em Psicologia, Londrina. v.8, n.1, p. 38-54, junh. 2017.

SOUZA, Marcos Antônio. A influência da fé no processo saúde-doença sob a percepção de líderes religiosos cristãos. Dissertação (Mestrado). Goiânia, 2009.

SOUZA, Marcela Tavares. Et al. Revisão integrativa: o que é e como fazer. Einstein. 2010; 8(1 Pt 1):102-6.

STROPPA, André. et al. Religiosidade e Saúde. Saúde e Espiritualidade: uma nova visão da medicina. Belo Horizonte, p. 427-443, 2008. 
TOMASSO, Claudia de Souza. et al. Conhecimentos e atitudes de docentes e alunos em enfermagem na interface espiritualidade, religiosidade e saúde. Revista Latino Americana de Enfermagem. São Paulo, 19(5): 8 telas, set-out. 2011.

VICENTE, Adriano R. Tarifa. et al. Religiosidade, suporte social e uso de antidepressivos entre idosos residentes em comunidade: um estudo de base populacional. Ciências e Saúde Coletiva. Belo Horizonte, 23(3):963-971, 2018.

ZANETTI, Guilherme Cia. et al. Percepção de Acadêmicos de Medicina e de Outras áreas da Saúde e Humanas (Ligadas à Saúde) sobre as Relações entre Espiritualidade, Religiosidade e Saúde. Revista Brasileira de Educação Médica. Uberaba, 42(1): 62-72, 2018.

Enviado: Outubro, 2019.

Aprovado: Março, 2020. 